Gustavo M. Martins · Francisco F. M. Wallenstein

Nuno V. Álvaro · Ana I. Neto · Ana C. Costa

\title{
Sampling strategies for biotope definition: minimal sampling area for selected groups of macroinvertebrates in the rocky subtidal of São Miguel, Azores
}

Received: 19 July 2004 / Revised: 4 April 2005/ Accepted: 15 April 2005 / Published online: 1 June 2005 (C) Springer-Verlag and AWI 2005

\begin{abstract}
Azorean rocky shores are mainly characterized by patchy algae-based communities with variable associated macrofauna. Characterization studies should therefore include quantitative information for both algae and macroinvertebrates. Unlike for the algae, minimal sampling areas are undefined for macroinvertebrates in the Azores. The present study defines the minimal area to be used for the assessment of the abundance of conspicuous benthic macroinvertebrate abundance. This study proposes methodologies to be used for a selected group of invertebrates when simultaneously undertaking quantifications of macroalgae.
\end{abstract}

Keywords Sampling areas - Macroinvertebrates · Rocky subtidal $\cdot$ Biotope definition $\cdot$ Azores

\section{Introduction}

Many recent studies have focused their attention on characterising shallow-water marine benthic communities (e.g. Southward and Orton 1954; Russell 1991; Zacharias et al. 1999; Foster et al. 2003). Recently interest has focused on habitat and community characterisation for marine conservation purposes (Mumby and Harborne 1999; Zacharias and Roff 2000). Although coastal ecosystem classifications for management purposes have been developed in the EU and USA, there are only two publications (Tittley et al. 1998; Tittley and

Communicated by H.-D. Franke

G. M. Martins · F. F. M. Wallenstein $(\bowtie) \cdot$ N. V. Álvaro

A. I. Neto · A. C. Costa

Secção de Biologia Marinha, Laboratório de Ficologia,

CIRN and Departamento de Biologia da Universidade dos Açores, Apartado 1422, 9501-801 Ponta Delgada,

São, Miguel - Açores, Portugal

E-mail: fmacedo@notes.uac.pt

Tel: + 35-129-6650000

Fax: + 35-129-6650100
Neto 2000) that outline a provisional benthic biotope classification for Azorean rocky shores following the lines of Hiscock (1995) and Connor et al. (1997). They focused only on stable rocky substrata (not those on mobile stones and cobbles) and were based on descriptive information. Recent studies which are being continued (Macedo 2002) use a quantitative approach to: (a) review the biotope classification of Tittley and Neto (2000); (b) characterise the communities associated with all rocky substrata; (c) define algal-based communities with associated benthic macrofauna; and (d) create a more complete biotope classification of the intertidal zone of São Miguel. These will also set the guidelines for methodologies to be used in further biotope surveys in the Azorean archipelago. The Azorean archipelago $\left(37^{\circ} 40^{\prime} \mathrm{N}\right.$ and $20^{\circ} 31^{\prime} \mathrm{W}$ ) is distributed unevenly along the Mid Atlantic Ridge. Its nine islands are volcanic in origin and the shores present a convoluted morphology, where high and steep cliffs alternate with rocky beaches of irregular rock sizes (Borges 2004; Morton et al. 1998). Most of the coast of São Miguel Island is subject to medium and high levels of wave action, with low levels restricted to harbours (Macedo 2002). These conditions create different habitat conditions for a wide variety of fauna and flora. Azorean rocky shores are mainly characterised by patchy algal communities with an associated macrofauna of various species. Biotope characterisation studies should therefore encompass quantification of the more conspicuous algae and macroinvertebrates simultaneously. Unlike for algae (Neto 1997), minimal sampling areas have not been calculated for macroinvertebrates in the Azores. These communities are too large to be studied as a whole hence the need to representative samples. Larger samples confer a higher degree of confidence in being a good representative of its population of origin while smaller samples keep sampling effort to a minimum (Weinberg 1978). A compromise is necessary to satisfy both criteria and minimal sampling areas resolve the problem. They are large enough to give accurate qualitative and quantitative information about the composi- 
tion of the community, and small enough to keep sampling effort within reasonable limits (Weinberg 1978).

There are two main methods for the assessment of minimal areas: (1) traditional species-area curves; and (2) similarity/diversity indices-area plots. These methods account for the determination of a minimal area for the whole community, but if the objective is to identify the minimal sampling area for determining abundances of a specific organism or a restricted group of organisms they are not appropriate.

Naturally occurring species assemblages are variable by nature, and spatial variability can occur at different scales ranging from biogeographic to local (Underwood and Chapman 1996, 1998). This applies to species assemblages as well as to single populations. As a consequence, minimal sampling area may vary with population parameters and with geographical location. Therefore it should be determined for each organism/ group of organisms and for each place or at least for each region.

As part of developing a methodology for biotope characterization on Azorean rocky shores, the present study defines the minimal area to be used for abundance assessment of conspicuous benthic macroinvertebrates. In areas where communities are mainly characterised by algae for biotope characterization, this study sets the quantification methodologies to be used for a selected group of invertebrates simultaneously with algal quantification.

\section{Methods}

The study was carried out on the sublittoral of São Miguel Island, Azores from February to March 2004 on 4 sampling sites (Fig. 1). The study location was selected from 15 possible sampling sites around the island using a table of random values.

The more conspicuous invertebrates were selected using empirical criteria such as representativeness in the habitats studied and low mobility, these were : sea stars [Ophidiaster ophidianus (Lamarck 1816), Marthasterias glacialis (Linnaeus 1758)]; sea urchins [Sphaerechinus granularis (Lamarck 1816), Paracentrotus lividus
(Lamarck 1816), Arbacia lixula (Linnaeus 1758)]; holothurians (Holothuria spp.); fire-worms [Hermodice carunculata (Pallas 1766)]; and tube-worms [Spirographis spallanzani (Viviani 1805)].

Three different depth levels were considered according to Neto (2001): (1) shallow water-5 m; (2) intermediate transition zone-15 m; and (3) deep water- $25 \mathrm{~m}$. At each depth level the total number of individuals was counted in four different areas $(7.5,15$, 22.5 , and $\left.30 \mathrm{~m}^{2}\right)-1.5 \mathrm{~m}$ wide transects associated to four length classes: 5, 10, 15 and $20 \mathrm{~m}$. Transect width was chosen based on preliminary tests counting organisms along $10 \mathrm{~m}$ long transects of varying width $(1,1.5$, and $2 \mathrm{~m}$ wide) with the help of PVC bars; counting easiness was the sole factor considered, and $1.5 \mathrm{~m}$ width chosen. Transect length categories were chosen to represent four levels of sampling effort, and $20 \mathrm{~m}$ considered the maximum effort possible. This decision was based on the time spent in counting organisms along three replicate transects $(20 \mathrm{~m}$ long and $1.5 \mathrm{~m}$ wide) at the maximum depth of $25 \mathrm{~m}$. Three replicates was the number chosen in the experimental design for invertebrate quantification procedures in the biotope characterization study. Invertebrate and algae quantification methodologies were planned to be executable together during only one dive and thus methodologies kept to a minimum of time consumption.

Transect location and geographic orientation were randomly chosen using a table of random values, and two replicate transects of each length were sampled.

Sampling strategy followed a fully orthogonal experimental design with depth (3 levels) and area (4 levels) as fixed factors.

Data were subject to analysis of variance (2-factor ANOVA), homogeneity of variances assessed using Cochran's $C$ test and data transformation applied when necessary (Underwood 1997), using the statistical software package GMav 5.0 (University of Sydney). Non metric multidimensional scaling was applied to data for trend identification in samples, SIMPER analysis used to identify organism contributions for sample grouping trends, and ANOSIM to test for differences between samples using the software package PRIMER (Clarke and Warwick 2001).
Fig. 1 Sampling sites on São Miguel Island

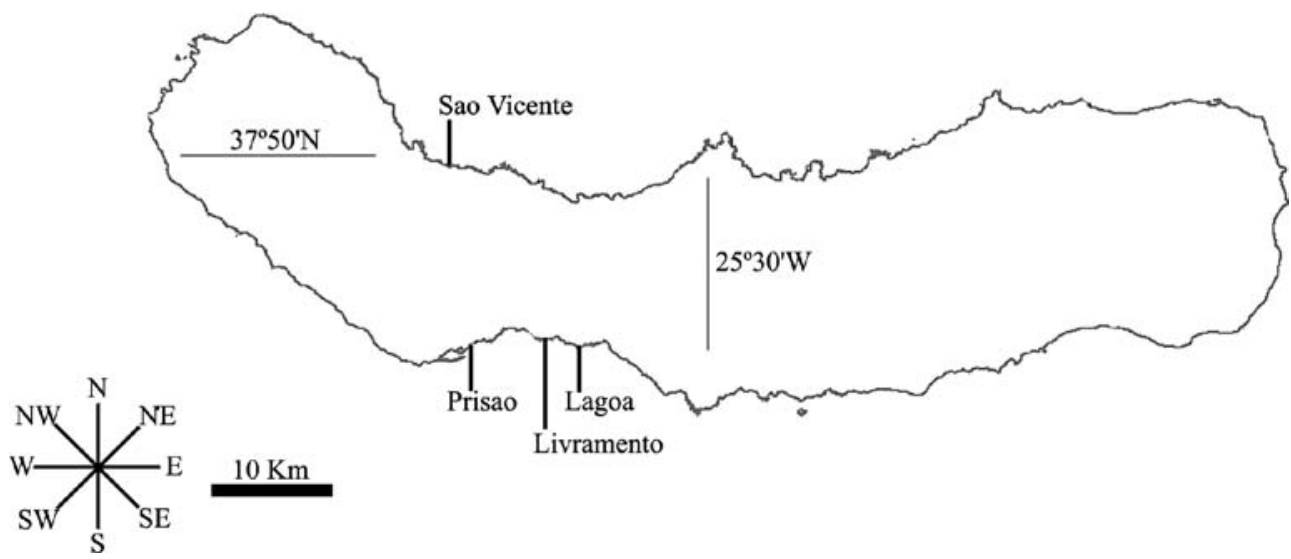




\section{Results}

Univariate analysis

Analysis of variance showed a significant variability associated with depth regarding sea stars, tubeworms and fire-worms (Table 1). The interaction between depth and area is significant in the case of sea urchins. No significant differences were identified for holothurians.

Figure $2 \mathrm{a}$ and $\mathrm{b}$ show that both sea stars and tubeworms present higher density at the shallower depth-D1contrary to what was observed for fire-worms (Fig. 2c) that showed higher density at higher depths-D3. Figure $2 \mathrm{~d}$ shows great variability of sea urchin density: (i) within depth classes - with less variability in the intermediate depth level D2; and (ii) between areas - with less variability in the longer transects of $15 \mathrm{~m}$ and $20 \mathrm{~m}$. Highest and lowest density values for sea urchins were found in the lowest and highest depths sampled (D1 and D3) and for the transect lengths of $5 \mathrm{~m}$ and $10 \mathrm{~m}$, respectively, tending to stabilize for the transect lengths of $15 \mathrm{~m}$ and $20 \mathrm{~m}$. A relatively constant density of sea urchins is observed at the intermediate depth (D2) independent of transect length. Density of sea urchins was constant with respect to depth for transect lengths

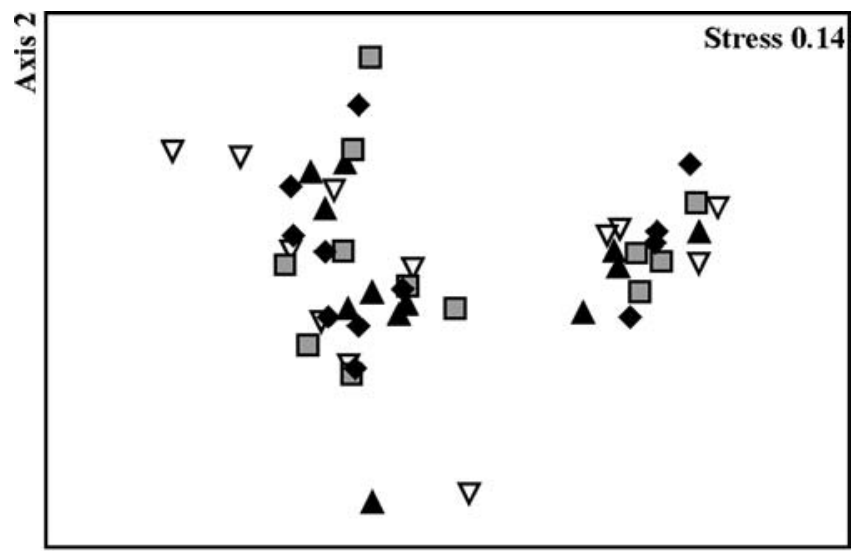

Axis 1

Fig. 3 Non metric Multidimensional scaling (nmMDS) groupings of samples labeled according to the four transect lengths considered for this study (filled triangle $5 \mathrm{~m}$, open triangle $10 \mathrm{~m}$, shaded square $15 \mathrm{~m}$ and filled diamond $20 \mathrm{~m}$ )

Table 1 ANOVA results comparing species abundance of selected macroinvertebrates at three depths and four sampling areas

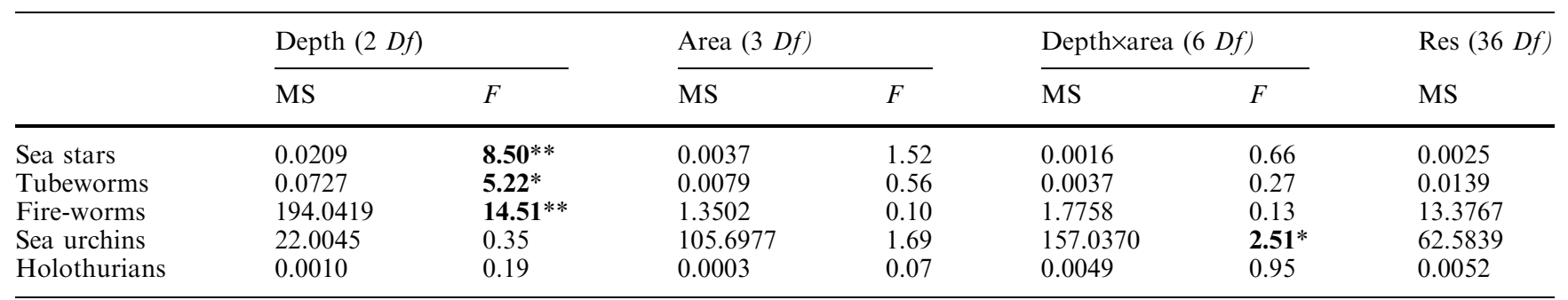

Bold text $=$ significant $P$ values $(P<0.05=* ; P<0.01=* *)$

Fig. 2 Mean abundance of macroinvertebrates $(+\mathrm{SE})$ at three depths (filled square $5 \mathrm{~m}$, open square $15 \mathrm{~m}$, shaded square $25 \mathrm{~m}$ ), where the $x$-axis represents transect length categories (m) and the $y$-axis represents density $\left(\mathrm{nm}^{-2}\right)$
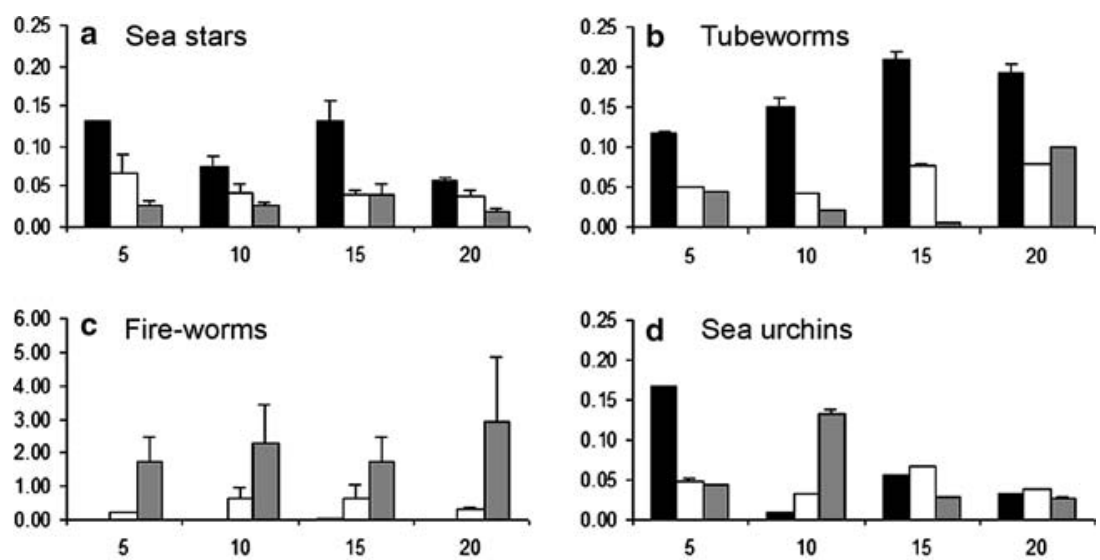

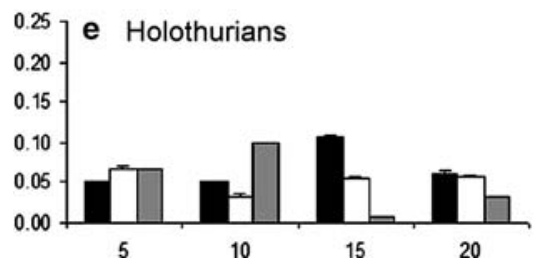




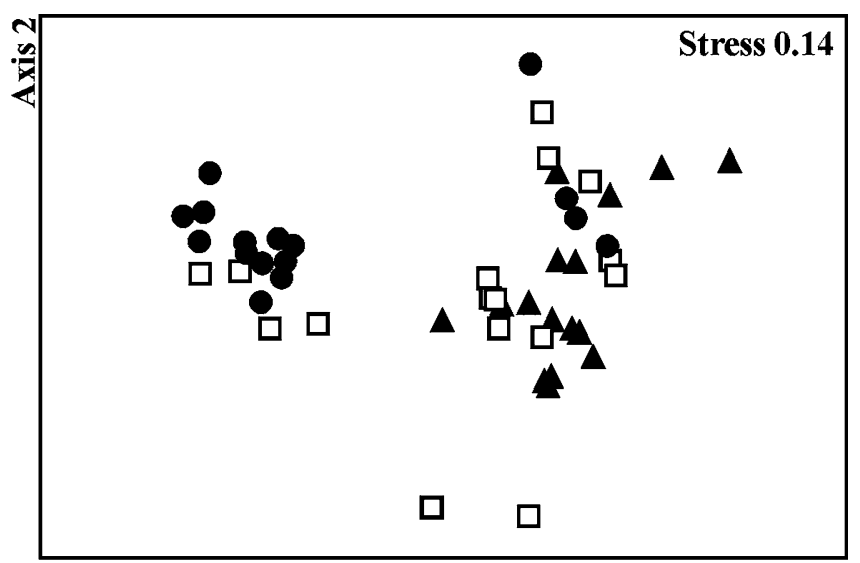

Axis 1

Fig. 4 Non metric Multidimensional scaling (nmMDS) groupings of samples labeled according to the three depth levels considered for this study (filled triangle $5 \mathrm{~m}$, open square $15 \mathrm{~m}$ and filled circle $25 \mathrm{~m})$

of $15 \mathrm{~m}$ or more. Holothurian density was relatively constant for both depth and area classes (Fig. 2e).

\section{Multivariate analysis}

Non-metric multidimensional scaling of samples (nMDS) showed no grouping associated to the factor area (Fig. 3). However, when depth is considered, patterns can be identified, namely on the horizontal axis between most of the samples taken at $25 \mathrm{~m}$ and $5 \mathrm{~m}$ depth, while $15 \mathrm{~m}$ depth samples co-occur with both groups (Fig. 4). On the vertical axis no separation can be identified. A higher variability was associated to samples taken at $5 \mathrm{~m}$ and $15 \mathrm{~m}$ depth.
For the separation of samples according to depth, SIMPER results (Table 2) showed that dissimilarity was lower between $5 \mathrm{~m}$ and $15 \mathrm{~m}$ (68.94) and between $15 \mathrm{~m}$ and $25 \mathrm{~m}$ (75.19), than that observed between $5 \mathrm{~m}$ and $25 \mathrm{~m}$ (84.28). Fire worms were the main cause of the dissimilarity between depth levels, and showed an increasing abundance with depth. Tube worms and sea stars - the second and third contributors for the dissimilarity - showed a decreasing abundance with depth, stabilizing down from the transition zone. Sea urchins and holothurians showed a constant average abundance across all depth levels.

ANOSIM test (Table 3) showed that all depth classes were significantly different from each other, being the most significant difference associated to the depth classes of $5 \mathrm{~m}$ and $25 \mathrm{~m}$.

\section{Discussion}

Results from univariate and multivariate analysis were consistent: depth was the main factor which contributed for density variation in the selected groups of macroinvertebrates considered by the present study. These showed a similar depth distribution pattern to that reported by Neto (2001) for algae: two distinct commu-

Table 3 ANOSIM analysis results when testing for differences between the three studied depths $(5,15$, and $25 \mathrm{~m})$

\begin{tabular}{lllll}
\hline Groups & $R$ statistic & $\begin{array}{l}\text { Significance } \\
\text { level (\%) }\end{array}$ & $\begin{array}{l}\text { Actual } \\
\text { permutations }\end{array}$ & $\begin{array}{l}\text { Number } \\
\text { Observed }\end{array}$ \\
\hline 5,15 & 0.128 & 0.2 & 999 & 1 \\
5,25 & 0.578 & 0.1 & 999 & 0 \\
15,25 & 0.229 & 0.6 & 999 & 5 \\
\hline
\end{tabular}

Table 2 SIMPER analysis results when testing for differences between macroinvertebrate mean abundances at the three studied depths (5, 15 and $25 \mathrm{~m}$ )

\begin{tabular}{|c|c|c|c|c|c|}
\hline Species & $\begin{array}{l}\text { Average } \\
\text { abundance }\end{array}$ & $\begin{array}{l}\text { Average } \\
\text { abundance }\end{array}$ & $\begin{array}{l}\text { Average } \\
\text { dissimilarity }\end{array}$ & $\begin{array}{l}\% \text { Contribution } \\
\text { to dissimilarity }\end{array}$ & $\begin{array}{l}\text { Cumulative } \% \\
\text { contribution }\end{array}$ \\
\hline \multicolumn{6}{|c|}{ Average dissimilarity $=68.94$} \\
\hline Fire-worms & 0.02 & 0.45 & 23.49 & 34.07 & 34.07 \\
\hline Tubeworms & 0.17 & 0.06 & 16.85 & 24.44 & 58.51 \\
\hline Seastars & 0.10 & 0.05 & 10.26 & 14.89 & 73.39 \\
\hline \multicolumn{6}{|c|}{ Average dissimilarity $=84.28$} \\
\hline & Group 5 & Group 25 & & & \\
\hline Fire-worms & 0.02 & 2.18 & 60.07 & 71.27 & 71.27 \\
\hline Tubeworms & 0.17 & 0.04 & 9.62 & 11.42 & 82.69 \\
\hline Seastars & 0.10 & 0.03 & 5.40 & 6.40 & 89.09 \\
\hline Sea urchins & 0.07 & 0.06 & 4.78 & 5.67 & 94.77 \\
\hline Sea urchins & 0.05 & 0.06 & 4.04 & 5.37 & 90.36 \\
\hline
\end{tabular}


nities at $5 \mathrm{~m}$ and $25 \mathrm{~m}$ depth separated by a distinct transition zone at $15 \mathrm{~m}$ depth. In the present study multidimensional scaling showed overlap of the samples taken at $15 \mathrm{~m}$ with those taken both at $5 \mathrm{~m}$ and $25 \mathrm{~m}$. Both ANOSIM R values (Table 3) and SIMPER dissimilarity values (Table 2) are consistent with these observations although the latter are generally high, and similarity between $25 \mathrm{~m}$ samples lower than for samples at shallower depths. The areas (transect lengths) used in the present study did not imply any significant variability in the density of the selected groups of macroinvertebrates. This might mean that the transect lengths considered were not sufficiently large to identify the minimum area for a sampling strategy with this kind of organisms. Nevertheless, Table 3 indicates sea urchin average abundance to be stable across depth classes which leads to the conclusion that the main effect of this interaction arises from the area factor (i.e. transect length). From Fig. 2d it was possible to associate such high variability mainly to the transect lengths of $5 \mathrm{~m}$ and $10 \mathrm{~m}$. Sea urchin density associated to longer transects (namely $15 \mathrm{~m}$ and $20 \mathrm{~m}$ ) appeared to be quite stable, and these could therefore be considered as the transect lengths to be used in future sampling strategies. In this context, given the diving time constraints and the need to combine sampling strategies for algae and invertebrates simultaneously in the same dive, and to minimize sampling effort, the area chosen for future macroinvertebrate sampling in the Azores was $15 \times 1.5 \mathrm{~m}^{2}$.

Acknowledgements The authors wish to thank Dr. I. Tittley (Natural History Museum, London) for editing and revising this paper and for general discussions that contributed significantly for its completion. This study inserted in the project POCTI/MGS/ 54319/2002 entitled "Biotope - Classification, Mapping and Modelling of Azores Littoral Biotopes", was funded by Fundação para a Ciência e Tecnologia (FCT) through OE and FEDER funds. It has also been partially funded by CIRN-Centro de Investigação de Recursos Naturais, Fundação para a Ciência e a Tecnologia. The experiments performed for the present study comply with the laws of the country in which they were performed.

\section{References}

Borges P (2004) Ambientes litorais nos grupos Central e Oriental do arquipélago dos Açores, conteúdos e dinâmica de microescala. Dissertação para a obtenção do Grau de Doutor, Departamento de Geociências, Universidade dos Açores, p 413

Clarke KR, Warwick RM (2001) Change in marine communities: an approach to statistical analysis and interpretation. 2nd edn. PRIMER-E, Plymouth
Connor D, Brazier DP, Hill TO, Northen KO (1997) Marine nature conservation review: marine biotope classification for Britain and Ireland, vol 1. Littoral biotopes, Version 97.06, JNCC Report, 229:1-361

Foster MS, Nigg EW, Kiguchi LM, Hardin DD, Pearse JS (2003) Temporal variation and succession in an algal-dominated high intertidal assemblage. J Exp Mar Biol Ecol 289:15-39

Hiscock K (1995) Classification of benthic marine biotopes of the north-east Atlantic. Proceedings of a BioMar-Life workshop held in Cambridge 16-18 November 1994. JNCC, Peterborough

Macedo FLWFM (2002) Biótopos do intertidal rochoso da ilha de São Miguel (Açores). Relatório de estágio para conclusão da Licenciatura em Biologia-Ramo de Biologia Marinha. Universidade dos Açores, Ponta Delgada, p 67

Morton B, Britton JC, Martins AMF (1998) Coastal ecology of the Azores. Sociedade Afonso Chaves, Ponta Delgada

Mumby PJ, Harborne AR (1999) Development of a systematic classification scheme of marine habitats to facilitate regional management and mapping of Caribbean coral reefs. Biol Conserv 88:155-163

Neto AI (1997) Studies on algal communities of São Miguel, Azores. Dissertação para a obtenção do Grau de Doutor em Biologia, especialidade de Biologia Marinha. Universidade dos Açores, Ponta Delgada

Neto AI (2001) Macroalgal species diversity and biomass of subtidal communites of São Miguel (Azores). Helgol Mar Res $55: 101-111$

Russell G (1991) Vertical distribution. In: Mathieson AC, Nienhuis PH (eds) Ecosystems of the World 24. Intertidal and littoral ecosystems. Elsevier, Amsterdam, pp 43-65

Southward AJ, Orton JH (1954) The effects of wave-action on the distribution and numbers of the comonner plants and animals living on the Plymouth breakwater. J Mar Biol Ass UK 33:1-19

Tittley I, Neto AI (2000) A provisional classification of algalcharacterised rocky shore biotopes in the Azores. Hydrobiologia 440:19-25

Tittley I, Neto AI, Farnham WF (1998) Marine algae of Flores. Azores: ecology and floristics. Bol Mus Munic Funchal Sup 5:463-479

Underwood AJ (1997) Experiments in ecology: their logical design and interpretation using analysis of variance. Cambridge University Press, Cambridge

Underwood AJ, Chapman MG (1996) Scales of spatial patterns of distribution of intertidal invertebrates. Oecologia 107:212-224

Underwood AJ, Chapman MG (1998) A method for analysing spatial scales of variation in composition of assemblages. Oecologia 117:570-578

Weinberg S (1978) The minimal area problem in invertebrate communities of mediterranean rocky substrata. Mar Biol 49:33-40

Zacharias MA, Roff JC (2000) A hierarchical ecological approach to conserving marine biodiversity. Conserv Biol 14(5):13271334

Zacharias MA, Morris MC, Howes DE (1999) Large scale characterisation of intertidal communities using a predictive model. J Exp Mar Biol Ecol 239:223-242 